\title{
Generic Substitution - A Challenge for Adherence in Primary Care and a Reason for Mistakes in Hospitals
}

\author{
Else-Lydia Toverud*
}

Department of Social Pharmacy, School of Pharmacy, University of Oslo, Norway

\begin{abstract}
Generic substitution was introduced in Norway in 2001, and the sale of these drugs had, by 2008 , reached $40 \%$ of the market shares in defined daily doses. Little is known whether generic substitution causes a poorer adherence than before in chronic patients or to what extent it can be a source of error when nurses handle medications. In three studies presented in this proceeding article patients on antihypertensive therapy and nurses in a big hospital were interviewed to look into this problem. The results from the studies show that generic substitution is an additional challenge both for the patients and for the nurses. The patients feel insecure about the situation, and it was even found that one in twenty took the brand product as well as the non-branded substituted product at the same time. In general they at least wished that they had had some information from their doctor before they came to the pharmacy. Also the nurses felt insecure and claimed not to have the knowledge needed to perform generic substitution. They felt that their role in being responsible for the changes for the patients easily could be a source of medication errors, and that the situation would probably ameliorate if the doctors prescribed the hospital's preferred drugs.
\end{abstract}

Keyword: Generic substitution, adherence, hypertension, primary care, hospital.

\section{INTRODUCTION}

The pharmaceutical market is strictly regulated in most European countries, and a number of different methods for pharmaceutical price control have been developed [1, 2]. Price reductions in the off-patent market can be achieved by for instance generic substitution. In Norway this system was introduced in 2001.

A generic product contains the same amount of the same active compound as the brand product, has $80-125 \%$ of its bioavailability, and has the same quality and safety. The sale of non-branded drugs on the Norwegian market is steadily rising and had by 2008 reached $40 \%$ of the market shares in defined daily doses [3].

In general adherence can easily be less than $50 \%$ in the case of patients on chronic drug therapy [4]. Little is known, however, whether the generic substitution causes an even poorer adherence among chronic patients or to what extent this intervention can be a source of error when nurses, who are often responsible for the substitution, handle medications.

The objective for the three studies in the present paper has therefore been to look into this problem carefully. Two populations of patients on hypertensive therapy in primary care have been interviewed, the first one with a qualitative method and the second one using a quantitative method.

Nurses in one of the biggest hospitals of the country have been interviewed quantitatively.

*Address correspondence to this author at the Department of Social Pharmacy, School of Pharmacy, University of Oslo, Norway;

Tel: +47 22856129; E-mail: e.l.toverud@farmasi.uio.no

\section{MATERIAL AND METHODS}

The first study [5] was performed with patients on antihypertensive therapy from five pharmacies in Oslo, using the qualitative method "focus group interviews". The material consisted of 22 participants ( 15 men and 7 women) in the age group 51-76 years. Five focus groups were held with four or five persons in each group, discussing adherence after their brand-name antihypertensive drug had been substituted to a non-branded alternative. The pharmacies had each got twenty invitation letters to give out to patients who fulfilled the inclusion criteria, and the focus groups were held when there was a representative number of participants included from each pharmacy.

In the second study [6] the material consisted of 174 outpatients between 50 and 80 years of age who were recruited from 14 pharmacies in Oslo and Bergen, the two largest cities in Norway. All the participants had been through the same sort of substitution as in the first study, that is that they had had their brand-name antihypertensive drug substituted with a non-branded alternative in a pharmacy on at least one occasion. The patients were personally interviewed, preferably in their own home. A semistructured questionnaire with 78 questions was used, where 28 of the questions were open-ended. The patients were also asked to show which drugs they actually used. The response rate was $65 \%$.

The material for the third study [7] was 100 nurses who were all employed in the same regional hospital (360 beds) in Norway. They all came from wards where a high number of medicines were used. The nurses were interviewed personally with a semi-structured questionnaire containing 67 questions. The response rate was $64 \%$.

All the participants in the three studies gave their written consent, and all the studies were approved both by the 
Regional Ethics' Committee and by the Norwegian Social Science Data Services.

\section{RESULTS}

\section{Study 1: Focus Group Discussions with Patients who had Changed to Generic (Non-Branded) Products}

The patients in the focus group discussions had the feeling that their adherence was "as bad after generic substitution as it had been before", and only 8 of the 22 patients claimed to be normotensive.

Just a few of the informants claimed that they always took the medicines as prescribed, whereas every second said that sometimes they did not take the tablets at all. Several of the 22 patients reported that they normally tried to ask for the branded product in the pharmacy, and three of them had managed to change back.

One person said:

"After all you would prefer what your doctor has prescribed"

On a direct question several patients revealed that they did not know what it was to get a generic product, and that it made them very insecure. One question back from an informant was as follows:

"The doctors prescribe what they find in their book, and the pharmacists sell you what they have in stock, don't they?"

Those who talked about differences between branded and non-branded products, mainly talked about physical differences such as form, colour and size.

One said:

\section{"I get square tablets now, the last ones were round."}

Regarding side effects some of the informants had felt dizziness or sickness after the substitution. A couple of them "admitted" afterwards by their own initiative that they were not sure if it was due to new side effects or if they had expected something to happen when the medicine was changed. Overall the participants were occupied with the importance of the pharmacy personnel having the right education to know what they do when they substitute products. Most of them said they trusted the pharmacy, whereas some felt that they just had to trust them:

"When they say in the pharmacy that it is the same ingredient, I have to trust them, I have no other choice. You cannot say to them: sorry, you are mistaken (laughing)."

The patients in the study relied, however, on their doctor and felt the situation would have been easier if he/she had informed them about generic substitution. Very few felt that they had got such information.

\section{Study 2: Personal Interviews with Patients who had Changed to Generic (Non-Branded) Products}

When the 174 personal interviews with patients in primary care were performed, one in three felt that generic substitution made keeping track of their medication more demanding. Twenty-nine percent said they were anxious when they started to use a generically prescribed drug. They felt it was easier for them to recognise the brand-name drug since the different non-branded ones often look alike both when it comes to packing and also to the tablets themselves. Eight percent felt that the effect of the drug had changed, and $15 \%$ reported having new or more side effects.

Five percent of the patients had been using more than one equivalent generic drug at the same time. They were all patients who used several different drugs and who also were getting their drugs from more than one pharmacy. In a few of these cases the patient had been hospitalised due to overdosing.

\section{Study 3: Personal Interviews with Nurses About Generic Substitution in Hospitals}

In the hospital study half of the nurses claimed that they had to substitute prescribed drugs daily even if they lacked knowledge about generic substitution, and even if it is the physicians' responsibility to prescribe the hospital's preferred drugs. About $60 \%$ reported that they also sometimes performed switches between drugs that did not contain the same active compound. Three out of four said that they seldom or never verified the feasibility of any form for substitution with the physician, and that it was seldom documented.

Forty-two percent said that they were aware of that medical errors had occurred as a result of substitution, and nine in ten wished the circumstances to be so that they would not have to substitute drugs.

\section{DISCUSSION}

All the three studies from the University of Oslo presented in this proceeding article, based on an oral presentation given in the $2^{\text {nd }}$ International Conference on Drug Discovery and Therapy, show that there are anxiety and insecurity involved when patients are getting generically substituted drugs.

As is said above adherence in patients on chronic drug therapy is a big problem. Patients have many reasons to be non-adherent, from the conscious ones, such as finding the price of a drug too high, the fear of side effects or a disbelief in the effect of the drug, to the more sub-conscious reasons such as forgetfulness or having misunderstood the drug dose or regimen. As a result of this, adherence is in most cases much lower than what was the intention with the prescription [4].

Not surprisingly it is found that many hypertensive patients have a blood pressure which is not under control [79]. When they have their brand products substituted generically, it is an additional challenge for adherence. As can be seen from Study 1 the patients say they have a bad adherence, something which corresponds well with that only eight out of 22 informants say they have their blood pressure under control. The generic substitution obviously make them anxious and insecure, and they are uneasy about the new drugs having a different colour, shape or taste.

In Study 2 [6] the same type of patients were interviewed in their own homes (Study 2). Also here we find that the patients feel insecure when starting with generic products. Their adherence is bad and some of them feel new side effects as well as that the effect is getting poorer. A frightening result in the second study is that one in twenty patients used the brand product as well as the generic 
product, having not understood that the generic product was an alternative to the product they had used before.

In both Study 1 and Study 2 the patients relied very much on their doctor and wished they had had more information from him/her. A better cooperation between the pharmacist and the doctor would probably have made the patients feel more safe about generic substitution. An alternative is that "generic prescribing" could have been used more extensively. As it is now, it is allowed in Norway, but is only used for $2 \%$ of the prescriptions.

In Study 3 where one hundred nurses in one of the country's biggest hospitals were interviewed about their experiences with generic substitution, it was obvious that also this group found their situation confusing. The doctors are not updated with the hospital's drug list when they write their prescriptions, and the nurses have to perfom the substitution. The participating nurses claimed that they could be so preoccupied with the substitution that they forgot about dosing and formulation, and medical errors occurred.

Generic substitution is definitely a successful strategy when comes to public savings. However, it is important to be aware of that the situation can lead to an even poorer adherence among chronic patients if health personnel are not updated and if they do not give the patients the information that is needed.

\section{CONCLUSION}

The situation for Norwegian hypertensive patients regarding generic substitution has been studied in three different projects using three different methods. What is found is that this form for substitution clearly is an additional challenge both for the patients regarding their drug adherence, and for the nurses who often have to substitute drugs without having enough knowledge. The increasing use of generic drugs is a success when regards savings in the health care sector, but both according to the patients and to the nurses interviewed, it seems that the doctors should have a more active role in making the system work.

\section{REFERENCES}

[1] Håkonsen H, Horn AM, Toverud, EL. Price control as a strategy for cost containment - what has been achieved in Norway in the period 1994-2004? Health Policy 2009; 90: 277-85.

[2] Aaserud M, Dahlgren AT, Køsters JP, Oxman AD, Ramsay C, Sturm H. Pharmaceutical policies: effects of reference pricing, other pricing, and purchasing policies. Cochrane Database Syst Rev 2006; (2). CD005979. 10.1002/14651858.CD005979.

[3] The Norwegian Association of Pharmaceutical Manufacturers. Facts and Figures 2009. http://www.legemiddelstatistikk.com/tf/ 2009/index.html (Accessed 28.04.2009)

[4] Cramer JA, Benedict A, Muszbek N, Keskinaslan A, Khan ZM. The significance of Compliance and persistence in the treatment of diabetes, hypertension and dyslipidaemia:a review. Int J Clin Pract 2008; 62(1): 76-87.

[5] Røise AK, Hogstad G, Toverud EL. Compliance in patients on antihypertensive therapy after generic substitution[in Norwegian]. Abstract. The Norwegian National Conference of Pharmacy 2004; p. 19.

[6] Håkonsen $\mathrm{H}$, Eilertsen $\mathrm{M}$, Borge H, Toverud EL. Generic substitution: an additional challenge for adherence in hypertensive patients? Curr Med Res Opin 2009; 25: 2515-21.

[7] Håkonsen H, Hopen HS, Toverud EL. Challenges concerning generic substitution in hospitals. Adv Ther 2010; 27(2): 118-126.

[8] Burnier M, Santschi V, Favrat B, et al. Monitoring compliance in resistant hypertension: an important step in patient management. J Hypertens Suppl 2003; 21: S37-42.

[9] Hajjar I,Kotchen TA. Trends in prevalence, awareness, treatment, and control of hypertension in the United States, 1988-2000. JAMA 2003; 290: 199-206. 